\title{
Organizational Culture and Knowledge Management: a Study of Dangote Cement Manufacturing Firms, Obajana, Kogi State, Nigeria.
}

\author{
${ }^{1}$ Icheme, Monday Ojochide, ${ }^{2}$ Ikharehon, Julius A. (Ph.D.) and ${ }^{3}$ Itoya Joy (Ph.D) \\ ${ }^{1}$ Department of Business Management, University of Nigeria Enugu Campus (UNEC) Nigeria. \\ ${ }^{2}$ Department of Business Administration, Ambrose Alli University, Ekpoma. Edo State, Nigeria \\ ${ }^{3}$ Department of Business Administration, Ambrose Alli University, Ekpoma. Edo State, Nigeria
}

\begin{abstract}
:
The objective of the study was to ascertain the role of organizational culture in knowledge management with particular reference to Obajana Cement Manufacturing Firms, Kogi State. The study employed secondary data mainly through the reviewed literature Findings revealed that supportive culture and innovative culture significantly influence knowledge sharing and knowledge creation while bureaucratic culture at times affects knowledge acquisition to some extent. The bureaucratic culture at times affects knowledge acquisition to some extent. Bureaucratic culture can be effective depending on the situation and work environment. The study concluded that organizational culture (Bureaucratic, supportive and innovative culture) strongly determines the extent to which knowledge management is implemented in the organization. Organization culture is a strong predictor of knowledge management, its success or failure to enhance the organization's sustained competitive advantage toward better performance. The study finally recommended that organizations will endeavor to adopt a bureaucratic culture as it tends to create the expectation among organizational members and influence management to provide a clear vision of purpose for knowledge management before the employees will embark on the implementation of knowledge management activities. Although supportive culture and innovative culture help organizations to meet up the demands and needs of customers through knowledge creation, acquisition, and sharing. Organization members should be re-oriented based on the essence of new knowledge to facilitate their job performance
\end{abstract}

Keywords: Organizational Culture, Knowledge Management.

\section{Introduction}

Organizations are currently facing challenges that force them to adjust and adapt to the current development. These organizations pass through different change processes when having to respond and adapt to new development trends either as part of their expansion or restructuring processes. The implication of change processes are often under-estimated by Senior Management and are not usually managed appropriately (Kamugisha, 2013). Since organizations are comprised of individuals with different talents, personalities, and goals, the organization will have a different culture. Some aspects of this culture change when the personnel do; other forms seem to be fixed and enduring. The anatomy of an organization's culture dictates how the business functions on a day to day basis and can strongly influence that organization's potential for success or failure. Also, the ability of such an organization and its management to cope and stand firm with change and encourage innovation equally impacts its mission effectiveness (Fahri, 2007) organizational performance and employees' commitment. Considering the current environment of global communication especially in Nigeria where there are rapid changes and constant access to information, innovation can be vital to an organization's survival through integrating employee commitment in line with culture. To Fahri (2007), it has been a serious problem to encourage creative and innovative work within a team, employees or squadron. This can be overcome through soliciting feedback from employees, encouraging open communication across companies or organizations and encouraging new ideas. Therefore organizations may 
likely take full advantage of opportunities that arise for learning and development when employees change positions and managers can encourage innovation by setting an example of trust and by sharing time and experience with employees.

However, organization culture through its assumptions, values, norms, and symbols critically determines the way organization's members perceive and interpret the reality within and around the organization, as well as the way they interact in that reality (Nebojsa, 2012). That is organizational culture affects the way in which an organization changes and by merging organizational culture and change strategy will lead to improvement and efficiency of the change process.

To Janicijevic (2011) organizational culture is a system of assumptions, values norms and attitudes, manifested through symbols which the members of an organization have developed and adopted through mutual experience and which help them determine the meaning of the world around them and how to behave in it. The assumptions, values, norms, and attitude that the organization's members display positively shape their perceptive schemes. Through their perception the attach meanings to occurrences and events within and outside the organization and understand the reality that surrounds them. The behavior, actions, and interactions of members of an organization appear due to the meaning that the reality of that organization has for them.

Culture is the sum of the beliefs that shape norms of behavior and dictate the ways things should be done in an organization (Dimitrios, \& Athanasios, 2014). Organizational culture perceived to have strategic fit can be aligned with the organization's commercial strategy. Hofstede (2001) asserts that culture is the collective programming of the mind that distinguishes the member of one group from another. Having a cultural insight helps to create awareness of the extent or degree to which organizations members are willing to accept change and a cultural assessment determine the root cause of the problems that need stronger performance.

Organization culture facilitates the perceptions /interpretation of events that are occurring in the workplace and how they influence the ways/methods/strategies of doing things are introduced. Culture can hinder organizations with the best strategy to exploit business opportunities in the environment and achieve its objectives. Organizations' ability to withstand, survive and make full progress determines how effective they are (Ama, 2012).

The influence of culture on organizations emanates through the societal structure, values, norms behavior and practices of organization participants which in turn affects their level of acceptance or rejection of knowledge management in the organization (Damgoje et al 2015).

Mojibi, Khoiasteh, and Ghamari (2015) assert that utilizing management knowledge tools and technique prior to implementing a new technology can collaborate with the human resource in knowledge implementation. The prerequisite for successful implementation of knowledge management involves gaining a complete understanding of the relevant business culture through different levels of organizational hierarchy as well as identifying vital factors for success.

Organizational culture is believed to be the most significant input to effective knowledge management and organizational learning because corporate culture determines values, beliefs and work systems that could encourage or impede both learning (knowledge creation) and knowledge sharing (Lia et al, 2005). Organizational culture (bureaucratic culture, supportive culture, and innovative culture) will affect organizational learning and the organization's capabilities and can guide it to change and innovate. Learning through individuals and the organization will lead to organizational innovation especially in knowledgeintensive industries like Obajana Cement Manufacturing Firms, Kogi State and that may be the only real source of sustained competitive advantage.

The concept of knowledge can be easily understood in two dimensions which include tacit knowledge and explicit knowledge. Tacit knowledge is mainly rooted in the popular sayings that people can know more than they can tell'. Tacit knowledge is personal, very hard to articulate fully, experienced-based, contextualize, jog specific, not acquired through formal education and training but held within both known 
and unknown to the holder, transferred through conversation and narrative and also capable of becoming explicit knowledge. While explicit knowledge exists in the form of sentences, words, documents, organized data, computer programmes and policy manuals. It can be processed, transmitted stored, shared and communicated to people to understand and apply appropriately in the organization

Any organization that intends to transit into the knowledge-based organization will ensure that its culture aligned with the requirements for knowledge management success. Though, the implementation of effective knowledge management has been a serious problem from transition knowledge hoarders into knowledge shares (Mizumori, 1998). Considering the nature and business operation of Obajana Cement Manufacturing Firms, Kogi State, one wonders what the culture of the organization is and whether or not its culture will enable knowledge management or hinder knowledge management to process for its competitive advantage in the industry, as the acceptance or rejection knowledge management is influenced/affected by employee's activities, meetings and attitudes and whether or not the employees' work style is conducive to the type of change (Tuggle and Shaw, 2000).

However, organizational culture is solely anchored in three variables which include; artifacts, espoused values and basic underlying beliefs of employees in the organization. Artifacts comprise the superficial level of what one sees, hears and feels when one works in a new organization with an unfamiliar culture, the espoused values are the organization's goals and philosophies espoused to justify statements and action taken by the organization while basic underlying beliefs are the unconscious, taken-for-granted assumptions, perceptions, thoughts, and feelings that are mainly the source of all values and actions.

Obajana cement factory is a subsidiary of Dangote Group of Companies; is located in Obajana Village in Lokoja Local Government Area in Kogi State, 200km southwest of Abuja (Nigeria Capital). The cement and power plant is located $25 \mathrm{~km}$ from Kabba Road junction which provides access to the roadway leading to Lokoja (The Capital of Kogi State) and beyond. The Gas Pipeline run from the gas manifold at Ajaokuta steel complex and includes sections along the Ajaokuta-Okene road and Oben Kaduna NNPC pipeline with the last section from Lokoja-Kabba junction to Obajana village.

The plant was first opened in 2006 with two F L Smidth designed cement production lines and with a capacity of 5.0 million metric tonnes per annum. Presently, Dangote's Obajana Cement Plant is the largest cement plant in Sub-Saharan Africa. Since inception, the Group has experienced phenomenal growth on account of the quality of its goods and services, its focus on cost leadership and efficiency of its human capital. Today, Dangote Group is a multi-billion Naira company poised to reach new heights, in every endeavor competing with itself to better the past.

The Group's core business focus is to provide local, value-added products and services that meet the 'basic needs' of the populace. Through the construction and operation of large-scale manufacturing facilities in Nigeria and across Africa, the Group is focused on building local manufacturing capacity to generate employment and provide goods for the people.

Therefore, it is based on these backgrounds that the study focuses on the effect of organizational culture on the implementation of knowledge management with particular reference to Obajana Cement Manufacturing Firms, Kogi State.

\section{Statement of the Problem}

Manufacturing organizations are known as knowledge-intensive organizations which have made them diversify into different sectors of the economy. Obajana Cement Manufacturing Firms still face internal challenges. The reason behind it is that manufacturing organizations or firms in the developing countries are not recognizing the processes for knowledge management in line with the organizational culture and face serious challenges while acquiring the knowledge due to its rapid growth. In additions, the organization is unable to meet the requirements of knowledge capabilities in its operational activities which are a big challenge to improve the efficiency and quality of production. 
Ignoring organizational culture and its capabilities affect new knowledge as its success or failure depends on the level of employees' acceptance or rejection aligned with cultural artifacts, espoused values and basic underlying belief in the organization.

Finally, lack of knowledge sharing culture has been a problem as it leads them towards the narrow vision of knowledge and makes it difficult for employees to work as a team. Equally the nature of knowledge acquisition system in the organization is not aligned with the organization culture and as a result, employees cannot keep themselves updated and the knowledge in large quality remains out of their reach. The question one asks remains how would new knowledge be aligned with organization culture considering the cultural variables which include; artifacts, espoused values, and basic beliefs.

\section{Objectives of the Study}

The main objective of the study is to determine the effect of organizational culture on the implementation of knowledge management in the organization. However, the specific objectives are:

1. to ascertain the extent to which supportive culture influence knowledge sharing implementation in Obajana Cement Manufacturing Firms, Kogi State. Nigeria.

2. how and to what extent bureaucratic culture affect knowledge acquisition implementation in Obajana Cement Manufacturing Firms, Kogi State, Nigeria.

3. to examine the extent to which innovative culture influence knowledge creation implementation in Obajana Cement Manufacturing Firms, Kogi State, Nigeria.

\section{Review Related Literature \\ The concept of Organizational Culture and Knowledge Management}

Culture is the totality of the beliefs that shape norms of behaviors and directs the ways of doing things in the organization. Culture presents the ways organizational participants perceive and react to actions and situations within and outside the organizational including the adoption of new knowledge and methodologies for its effective implementation. An organization with the best strategies but lacks basic cultural values and beliefs will fail as good management aligned with culture to create and exploit business opportunities and also influence marking and Knowledge management featured to increase the knowledge creation ability and awareness in organizations. Knowledge management is developed for the purpose of ensuring knowledge quality and aim of knowledge while gathering it and make it accessible through maps, books, and hypertext tools; to develop a knowledge-intensive culture where employees can be encouraged to share their knowledge and at the same time put more effort to acquire knowledge from other employees' experiences and finally, to develop a culture through which people can be connected like web using organizational facilities, space, time and tools (Gilus et at, 2000). Knowledge management is the process of capturing, developing, sharing and effectively using organizational knowledge (Davenport, 1994). It is a multi-disciplined approach to achieving organizational objectives by making the best use of knowledge. Knowledge is a fact, feelings or experiences known by a person or group of people. To Kalpic and Bernus (2006), knowledge is present in ideas, judgments, talents, root causes, relationships, perspectives, and concepts. Knowledge correlates with customers, products, processes, culture, skills, experience and knowhow. Knowledge determines the extent a particular event and actions are perceived and interacted with organizational members. Although the Nigeria manufacturing sector is currently facing serious challenges in a global market, knowledge management appears to provide viable strategies to overcome those problems such as cultural diversity in terms of cultural artifacts, values, and basic beliefs. This can be made possible through knowledge integration and transfer to all organizational members. In the light of the strategic value of Dangote Product, Dangote Cement should recognize the need to manage affectivity its intellectual staff as knowledge management provides the framework and techniques that are required to transform the firm into a global manufacturing industry.

\section{Variables Clarification}

\section{The relationship between Supportive Culture and Knowledge Sharing}

Knowledge sharing is very vital to organizational success. The success factors in business operation marketing activities as associated with supportive culture in the organization. Knowledge management 
centers on the development of a set of shared organizational values and identities, facilitating interpersonal interaction and collaboration.

Organizational culture (that is, supportive culture) ensures that new knowledge created is shared among units, sections or departments within the organization to enhance its sustained competitive advantage. Knowledge created that is not in line with the values and beliefs of the employees will not be sustained and support as employees will continue to neglect such knowledge. Despite cultural values and beliefs, ownermanagers are still successful economically due to their strategy in knowledge acquisition and sharing which has been facilitated by a supportive culture in the organization.

\section{The relationship between Bureaucratic Culture and Knowledge Acquisition}

The level of knowledge acquisition among employees depends on the degree and type of organizational culture. Although bureaucratic culture emphasizes on laid down procedures/principles guiding the acquisition of any new knowledge, a company can devote itself to develop knowledge management strategies, creating a desirable organizational culture and adopting proper information technology tools and techniques to enhance the implementations of knowledge management (that is, knowledge acquisition, documentation, transformation, creation and application).

Bureaucratic culture combined with the high need for power ensures adequate acquisition knowledge to enhance organization's sustained competitive advantage. The problem to managers is to determine which characteristic of culture can quickly acquire and allocate new knowledge Organizational culture that encourages knowledge sharing and openness is more conducive to the implementation of knowledge management (knowledge acquisition, transformation, creation, accumulation, and diffusion),

\section{The relationship between Innovative Culture and Knowledge Creation}

Organizational culture (innovative culture) is believed to be the most significant input to effective knowledge management (knowledge creation) and organizational learning because innovative culture determines values, beliefs and work systems that could encourage or impede both learning (that is, knowledge creation) and knowledge sharing (Alavi and Leidner, 2001)

Innovative culture will affect knowledge creation, organizational learning and the organization's capacities and can guide it to change and innovate. Knowledge creation through individuals and the organization will lead to organizational innovation especially in knowledge-intensive industries like Dangote, Obajana Cement Manufacturing Firms and that will be the only source of sustained competitive advantage. The purpose of' knowledge management is to pursue innovative culture so that an organization can maintain sustained competitive advantage and to make an organization change and innovate through organizational creation. Innovative culture combined with the high need for achievement is related to knowledge creation for the organization's sustained competitive advantage in the industry.

\section{The relationship between Organizational Learning, Organizational Cultures, Knowledge Creation, Sharing, and Acquisition.}

Organizational learning in different industry structure will positively impact on organizational innovation and more organizational innovation will lead to higher brand performance as in Obajana Cement Manufacturing Firms. Though, market orientation through supportive culture and innovative culture has a positive significant effect or organizational learning and organizational innovation (Gold, Malhotra and Segar, 2001). Market orientation has a positive impact on the way and manner innovative culture is administered and organizational learning has an indirect relationship with organizational performance through organizational innovation.

Chang and Lee (2007) in their study revealed that both supportive culture and innovative culture have a positive influence on knowledge sharing, knowledge acquisition, knowledge creation and knowledge diffusion and also innovative culture has the greatest effect on innovation. Knowledge acquisition and sharing, knowledge storage and knowledge diffusion all have a significantly positive influence on technical innovation. 
Weeawardena, O'cass, and Julian (2006) assert that knowledge infrastructure comprising technology, structure, and culture including knowledge process architecture of acquisition, conversion, application, and protection are vital organizational capabilities and these capabilities will have a direct and positive correlation with organizational effectiveness. Knowledge acquisition is positively associated with organizational learning, organizational innovation, organizational growth and competitive advantage while organizational culture (bureaucratic culture, supportive culture, and innovative culture) play vital and moderating roles in knowledge creation, acquisition, sharing and organizational innovation relationships.

Collaborative culture encourages the development of organizational learning which at the same time has a significant effect on business performance. Having more organizational culture shared values does not only directly incur higher managerial performance through sharing organizational culture. See the research model below.

\section{Empirical Review}

A study on knowledge management and the Nigerian culture: A round peg in a square hole? Was conducted by Damgoje-Ayodele \& Ellis (2015) in Australia, the objective of the study was to determine the extent to which Nigerian culture influences organizational culture which in turn affects knowledge management practice in Nigerian organizations. The study employed a descriptive survey method and data generated from the respondents' responses were analyzed using a simple percentage. Findings showed that the hierarchical nature of the Nigerian society allows decision making which otherwise affects knowledge management practices in Nigerian organizations. Also, Nigeria as a masculine based culture mainly characterized by the propensity to achieve may align with the problem of employee existing organization due to lack of trust. Equally, the short-term orientation of Nigerian organization affects commitment to relationships and values associated with motivating employees', the study concluded that lack of trust is common in Nigerian organizations which result from the religious and tribal diversities in Nigeria. The study, however, recommends that since some organizational cultures do not support adoption of new knowledge management, therefore, management will intensify efforts to ensure that any new knowledge to be adopted, implemented and practiced is in line with the existing organizational culture to enhance its level of acceptance.

Lia, Change, and Yueh (2012) conducted a study on the relationship between organizational culture, knowledge acquisition, organizational learning and organizational innovation in Taiwan's banking and insurance industries. The specific aim of the study was to determine the relationship between supportive culture and knowledge acquisition, organizational learning, and innovation in the banking and insurance industries. The study adopted a descriptive survey research design, 23 out of 100 financial enterprises were used as the sample size for the study. In the same vein, a total of 785 questionnaires were administrated and 449 were valid and used for analysis. The studies apply a correlation relationship to the extent of the relationship to ascertain the extent of the relationship between the independent variable and the dependent variables. Findings showed that there is a positive significant relationship between supportive culture and knowledge acquisition and other variables under study. Also, organizational culture affects organizational learning and innovation through knowledge acquisition. The study concluded that organizational culture in banking and insurance organizations significantly affect knowledge sharing and knowledge acquisition especially when the bureaucratic culture is negatively associated with knowledge acquisition; both innovative culture and supportive culture are related to knowledge sharing and acquisition. The study, however, recommended that organizations should adopt a supportive culture that will lead to innovation and help them to absorb the influences from organizational culture, knowledge acquisition, and organizational learning and thereby strengthen organizational innovation.

\section{Theoretical Framework}

This study is anchored on the theory of organizational learning propounded by Albert Bandura in (1977). Organizational learning theory is a modified context of specific learning by multiple teams and team members with different cultural backgrounds to translate knowledge into actions and to evaluate those actions to create and share knowledge within an organization. Organizational learning relates to the ability of an organization to actively create, and use knowledge with outcomes which must be in consonance with the peoples' cultural artifacts, espoused value and basic beliefs. Cultural artifacts are difficult to measure and 
they deal with organizational attributes that be observed, feel and heard as an individual enters a new culture. Cultural values deal with the espoused goals, ideals, norms, standards and moral principles, and are usually the level that is measured through survey questionnaire while underlying assumptions (beliefs) deals with phenomena that remain unexplained when insiders are asked about the values of the organizational culture. Information is gathered in this leve1 by observing behavior carefully to gather underlying assumption because they are sometimes taken for granted and not recognized. The essence of organizational culture lies in this level as it determines the level of acceptance or rejection of knowledge management.

\section{Strategies to Achieve the Stated Objectives}

I. To determine the extent to which supportive culture influence knowledge sharing implementation in Dangote, Obajana Cement Manufacturing Firms, Kogi State. This objective would have been achieved if descriptive survey design was employed and data collected from respondents (employees) of the firm through structured questionnaire were analyzed, used correlation coefficient and the t-statistics to determine the level of significance. Although findings from the reviewed literature indicate that there is a positive significant relationship between the two variables. Knowledge sharing depends on the extent of supportive culture is adopted. Knowledge sharing is the process of ensuring that organizational members and units have access to the new knowledge for its effective usability to enhance organizational performance and productivity. Supportive culture leads to general acceptance of knowledge management to enhance organization's sustained competitive advantage. The information about an organization may affect the extent to which employees accept or reject new knowledge to be shared among individuals and units.

2. How and to what extent bureaucratic culture affect knowledge acquisition implementation in Dangote, Obajana Cement Manufacturing Firms, Kogi State. This objective would have been achieved if primary data is employed. Then the data collected through questionnaire would have been analyzed using regression analysis and t-statistic to determine the significance level. However, findings from the reviewed literature showed that there is a positive significant association between bureaucratic culture and knowledge acquisition in the organization. Bureaucratic culture is a strong indicator of knowledge sharing, as it determines the extent of new knowledge is acquired by the organizational members. Knowledge acquisition is the process of searching for, recognizing of and assimilating of potentially valuable knowledge often from outside the organization. The organization considered the norms and values principles and procedures before accepting any new knowledge and if such knowledge is contrary to its value system, it is rejected.

3. To determine the extent to which innovative culture influence knowledge creation implementation in Dangot, Obajana Cement Manufacturing Firms, Kogi State.

This objective would have been achieved if primary data is employed through a questionnaire. The data generated from respondents responses would have been analyzed using correlation analysis. Findings would have shown that there is a positive significant relationship between the two variables. Although from the reviewed literature, findings revealed that innovative culture influence knowledge creation in the organization. Employees have different cultural belief and orientation and as a result, affect their level of knowledge creation. Knowledge creation involves developing new knowledge or replacing existing knowledge with new content inside the boundary of the organization and/or in conjunction with the partners' culture. Employees' perception, feelings, and moral belief invariably affect their level of new knowledge creation. Employees strive and perform higher in organizations that adopt innovative culture as it helps them to enhance sustained competitive advantage over other organizations in the same industry.

Organizational culture is a strong indicator for assessing the level of knowledge creation, acquisition, sharing, transfer and implementation/usability in the organization. It determines whether the knowledge management is in conjunction with the cultural artifacts, espoused values and basic underlying beliefs of the people in the organization which may affect the level of acceptability or rejection of such knowledge.

\section{Conclusion}

Organizational culture is a set of implicit beliefs held by members of a group that determines how the group behaves interacts and responds to its environment. Culture consists of core values and beliefs that are embedded in tacit preferences about what the organization should strive to attain and how it should do it. Because organizations are made up of individuals with different talents, personalities, and goals, the 
organization will have a distinct culture which includes bureaucratic culture, supportive culture, and innovative culture. Some aspects of this culture change when the personnel do; other aspects are likely to be fixed and enduring. The anatomy of an organization's culture focused on how the business of the organization functions on daily basis and can strongly influence the organization's potentials for success or failure.

Also, the ability of an organization and its leaders to accept and cope with change and encourage knowledge creativity and innovation also affect mission effectiveness. As knowledge management is set of relatively new organizational activities that are aimed at improving knowledge, knowledge related practices, organizational behavior and decisions and organizational performance; organizational culture directly affects the extent new knowledge is perceived and valued by employees. Any aspect of new knowledge (knowledge creation, sharing, transfer, conversion, integration etc.) that is not in cognizance with organization's culture will fail because organizational culture determines the social context (consisting of norms and practices) that determine who is expected to control what knowledge as well as who must share it and who can hoard it.

\section{Recommendations}

In the height of the findings of this study, the following are recommended.

I. Organizations should endeavor to adopt a bureaucratic culture as it tends to create the expectation among organizational members and influence management to provide a clear vision of purpose for knowledge management before the employees will embark on knowledge management activities.

2. Organizational culture should be modified to suit or accommodate the present knowledge to enhance organizational performance.

3. Organizational members should be re-oriented based on the essence of new knowledge to facilitate their job performance.

4. Management should ensure that any new knowledge to be introduced should be embedded in the organizational culture.

5. Employees' values and beliefs should be given adequate consideration by management before the introduction of new knowledge as their resistance leads to failure.

6. Organizations should adopt the supportive culture and innovative culture to enhance their sustained competitive advantage over others in the same industry.

\section{References}

[1] Abili, K.; Thani, F. N.; Mokhtarian, F. and Rashidi, M. M. (2011), The Role of Effective Factors on Organizational Knowledge Sharing. International Conference on Education and Education Psychology, Procedia-Social, and Behavioural Sciences, 29(20 1 1), 1701-1706.

[2] Alavi, M. and Leidner, D. E. (2001), Review Knowledge Management and Knowledge management systems; conceptual foundations and Research Issues Management Information System Quarterly, 25 (1), 107-136

[3] Amah, E (2012), corporate culture and Organizational Effectiveness: A study of the Nigerian Banking Industry. European Journal of Business and Management; 4(8), 212-229.

[4] Anand, A. and Singh, M. D. (2011), Understanding Knowledge Management: A Literature Review International Journal of Engineering Science and Technology, 3(2), 926-939.

[5] Blake, J. and Laurence, P. (1989), The ABC' of management, Cassel Educational limited.

[6] Chang, S. C.; and Lee, M. S. (2007). Effects of Organizational Culture and Knowledge Management Mechanisms on Organizational Innovation: An Empirical Study in Taiwan. The Business Review, 7(1), 295-301.

[7] Damgoje-Ayodele \& Ellis (2015) Knowledge Management and the Nigerian culture, a round peg in a square hole? The African Journal of Information System, 7(1) 
[8] Davenport, T. H. (1994), Saving Information Technology's Soul: Human-Centered Information Management. Harvard Business Review, 72(2), 119-131.

[9] Delong, D. W., and Fahey, L. (2002), Diagnosing Cultural Barriers to Knowledge Management. Academy of Management Executive 14(4), 113-127.

[10] Dimitrios, B. and Athanasios, K. (2014), The Impact of Leadership and Change Management Strategy on Organizational Culture, European Scientific Journal, 10(7), 45 1-470.

[11] Donate, M. I. and Guadamillas, F. (2010). The Effect of Organizational Culture

[12] Epetimehim, F. M., and Ekundayo, 0. (2011). Organizational Knowledge Management: Survival Strategy for Nigeria Insurance Industry. Journal of Social Sciences 1(2), 21-31.

[13] Fahri, K. (2007). The Twenty-First Century Leader: Social Artist, Spiritual Visionary, and Cultural Innovator. Global Business and Organizational Excellence, 44-50

[14] Gold, A. H.; Malhotra, A. and Segar, A. H. (2001), Knowledge Management, Organizational Capabilities Perspective Journal of Management Information System, 18 (1), f 185-214.

[15] Guptill, J. (2005). Knowledge Management in Health Care, Journal of Health Care Finance, 31(3), $10-14$.

[16] Guus, S., Hans, A.; Anjo, A; Robert, D. H; and Nigel, 5. (2000). Knowledge Engineering and Management: The Common KADS Methodology. Published by MIT Press

[17] Hall, D. T. and Fukami, C. V. (1979), Organizational Design and Adult Learning Research in Organization Behavior JAI, Press, Inc.

[18] Hofstede, G. (2001). Culture Consequences: Comparing Values, Behaviours, Institutions, and Organizations Across Nations. SAGE. 